\title{
Laboreal
}

Volume $5 \mathrm{~N}^{\circ} 2$ | 2009

Varia

\section{As imagens no PowerPoint}

Las imágenes en Powerpoint

Les Images dans powerpoint

The images in PowerPoint

\section{Luc Desnoyers}

Tradutor. Rita Gil Mata e Marianne Lacomblez.

\section{OpenEdition}

\section{Journals}

\section{Edição electrónica}

URL: http://journals.openedition.org/laboreal/9948

DOI: 10.4000/laboreal.9948

ISSN: 1646-5237

\section{Editora}

Universidade do Porto

\section{Refêrencia eletrónica}

Luc Desnoyers, "As imagens no PowerPoint », Laboreal [Online], Volume 5 N² | 2009, posto online no dia 01 dezembro 2009, consultado o 10 outubro 2019. URL : http://journals.openedition.org/laboreal/ 9948 ; DOI : 10.4000/laboreal.9948

Este documento foi criado de forma automática no dia 10 outubro 2019.

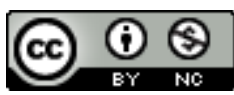

Laboreal está licenciado com uma Licença Creative Commons - Atribuição-NãoComercial 4.0 Internacional. 


\title{
As imagens no PowerPoint
}

\author{
Las imágenes en Powerpoint \\ Les Images dans powerpoint \\ The images in PowerPoint
}

\section{Luc Desnoyers}

Tradução : Rita Gil Mata e Marianne Lacomblez.

\section{REFERÊNCIA}

Artigo original : Desnoyers, L. (2007). Les Images dans powerpoint. Studies in Communication Sciences, 7, 2, 85-98.

\section{Introdução}

1 O aparecimento dos projectores electrónicos há cerca de uma quinzena de anos, favoreceu a utilização de imagens projectadas, nas comunicações públicas de todo o tipo, desde os congressos científicos às comunicações internas de empresas. Este desenvolvimento efectuou-se grandemente em torno de um programa informático que se tornou dominante, PowerPoint, que dirige praticamente tanto a concepção como a gestão das imagens em todos os contextos.

2 O recurso massivo ao PowerPoint (PPT), sobretudo nos Estados Unidos, suscitou críticas por vezes aguerridas, e em particular de parte de um dos melhores teóricos da gráfica da comunicação, Edward Tufte (2006). Partilhadas por muitos, as críticas denunciam, entre outros, o recurso sistemático a certas imagens de texto, a listas com marcas, vistas como um atalho abusivo e simplista servindo como substituto ao texto discursivo; elas denunciam também o recurso a uma panóplia de engenhos que vão desde as técnicas de animação de imagem mais simplistas passando pelo abuso de ornamentações gráficas, o "chart junk" (ruído gráfico) que Tufte denuncia no conjunto das suas obras. Os comentadores de Tufte não são no entanto unânimes (Doumont, 
2005). Mas a força é de constatar que todos os escritos não são mais que opiniões, já que nenhum repousa sobre um estudo sistemático do uso que é realmente feito do PPT. Sabemos, efectivamente, muito poucas coisas precisas sobre a utilização que é feita do PPT, como sublinhava recentemente Stoner (2007). O presente estudo tenta fazer um primeiro balanço quantitativo desta utilização, e em particular das imagens que animam os ecrãs com o PowerPoint e da sua concepção, sobretudo de um ponto de vista gráfico.

3 Um estudo quantitativo da utilização do PowerPoint embate em dois grandes problemas. O primeiro diz respeito à amostragem. Como, com efeito, reunir uma amostra representativa das utilizações de um programa informático que se estima ser usado por 300 milhões de utilizadores no mundo e que gera anualmente milhares de apresentações? O acesso aos documentos produzidos é um desafio na medida em que estes podem nunca ser difundidos, ou são submetidos a uma circulação restrita, tanto como podem ser largamente acessíveis, por exemplo via Internet. O segundo diz respeito ao recenseamento das imagens a analisar, que deve fazer-se recorrendo a uma grelha de classificação extensiva. Desenvolvemos uma para o estudo das comunicações científicas (Desnoyers, 2005a) que serviu de base à presente investigação. Esta taxonomia retém tês grandes categorias : os tipogramas, imagens de texto (listas com marcas, textos discursivos, tabelas, organigramas, etc.); os analogramas, representações de dados quantitativos figurados por diferentes signos gráficos (pontos, curvas, etc.) num espaço cartesiano; os cosmogramas, representações icónicas de entidades materiais. Adaptada às necessidades presentes, esta grelha serviu aqui de base à análise das imagens no PPT.

\section{Amostragem}

4 O motor de busca Google permite aceder aos documentos PowerPoint disponíveis na Internet. À execução (no dia 1 de Maio de 2007) da investigação pedindo a apresentação de todos os documentos marcados com o sufixo ".ppt", portanto concebidos com o PowerPoint e identificados como tal, o motor de busca apresenta as coordenadas de cerca de 1000 destes documentos, que constituíram a população em estudo. Sobre estes 1000, apresentados 10 por página, retivemos de modo sistemático a terceira apresentação de cada página, gerando assim uma amostra aleatória de 100 apresentações, que foram integralmente copiadas para o disco duro. A análise debruçou-se assim sobre 2739 páginas-ecrãs, excluindo as páginas-título e as páginas finais (agradecimentos, solicitação de questões, referências, etc.).

\section{Codificação e análise}

536 parâmetros foram retidos para a análise dos documentos.

6 Estes compreendem :

1. Indicadores da origem e da natureza das apresentações: categoria de autor (ensinoinvestigação, organismos públicos e governamentais, consultores, fabricantes), país de origem, data, tamanho do documento, língua utilizada, assunto tratado, objectivo da apresentação (informação, promoção), utilização prevista (apresentação no ecrã vs. acompanhamento de uma apresentação oral). 
2. Descritores dos tipos de apresentação utilizados. Um estudo preliminar conduziu-nos a definir as categorias seguintes : de um lado as imagens textuais (listas com marcas, textos discursivos, organigramas ou esquematizações textuais), de outro lado as imagens não textuais, incluindo as fotografias informativas (pessoas, locais, objectos descritos), os esquemas (incluindo reproduções de páginas de sítios Internet), as ilustrações inseridas para fins ornamentais, os analogramas e os quadros. É sobretudo sobre estes indicadores que se concentra o presente artigo. Tratar-se-á de relatar o número de páginas comportando um tipo de imagem, e compreendemos que uma mesma página pode comportar vários.

3. Indicadores de escolhas gráficas : polaridade da apresentação, cor do fundo, presença de um modelo de página, fonte dos caracteres utilizados nos títulos ou no texto, tamanho e cor dos caracteres, utilização de técnicas de animação numa página-ecrã ou durante as transições de uma página a outra.

7 Os dados foram reunidos em quadros produzidos com a ajuda do programa informático Excel e as compilações e análises estatísticas descritivas foram elaboradas com o apoio do mesmo programa. As populações de dados, não se apresentando conformes à distribuição normal, levaram-nos a ter em conta as medianas assim como as médias e a utilizar os estudos de correlação com parcimónia e prudência.

\section{Origem e natureza das apresentações}

8 A categoria de autores mais importante é a que provém dos meios de ensino e de investigação, com um total de 43 pessoas sobre 100. Seguem-se os consultores privados com 28, os serviços públicos e governamentais com 16, os fabricantes de objectos materiais com 7, e em 6 casos, não foi possível identificar a origem do autor.

O tamanho dos documentos é, em média de 27,4 páginas e de 1,45 megabytes por apresentação. A variabilidade é no entanto considerável : o máximo é de 112 vezes ( 1 a 112 páginas) ou de 191 vezes (0,056 a 10,1 MB) maior que o mínimo. o tamanho informático não é, de resto, relacionado com o número de páginas, mas com a presença de páginas contendo imagens não textuais (esquemas, fotos, quadros, ilustrações ornamentais) sobretudo importadas de outros documentos sem a preocupação de reduzir o tamanho dos ficheiros; ele não tem nenhuma relação com o número de páginas de texto seja sobre que forma este esteja. Ao contrário, o número total de páginas é claramente relacionado com a utilização de imagens textuais.

1061 dos 100 documentos parecem destinados à projecção acompanhando uma apresentação oral, em particular em congressos científicos e em conferências diversas, e 35 parecem manifestamente destinados à simples leitura ou à consulta sobre o ecrã ; a natureza de 4 documentos (de origem asiática) não pôde ser determinada.

11 Quanto ao seu conteúdo, podemos reagrupar os 100 documentos em 3 categorias : 58 tratam de serviços, 26 de conhecimentos ou de resultados de investigação e 11 de produtos materiais. Os temas mais frequentemente tratados dizem respeito à informática em $30 \%$, à educação em $18 \%$, ao domínio biomédico e biotecnológico em $11 \%$ e à energia e recursos naturais em $6 \%$; resta dizer que os temas abrangidos pelos $35 \%$ dos documentos restantes são muito variados. Os documentos parecem produzidos com a intenção de fornecer informação em $56 \%$, de promover um produto ou um serviço em $40 \%$.

12 A variabilidade é importante também no que diz respeito à relação entre os autores e os temas abordados. Se os autores vindos dos meios de ensino e de investigação 
constituem a coorte mais importante, a sua produção serve para a difusão de saberes (conteúdos de ensino, resultados de investigação) assim como para a facilitação da utilização de serviços educativos, por exemplo, os serviços bibliotecários. São sobretudo estes que abordam os temas de educação, o domínio biomédico e biotecnológico, a informática. As firmas de consultores, o segundo grupo em importância, abordam sobretudo a oferta de serviços informáticos. Os serviços públicos, de nível municipal a nacional, terceiro grupo em importância, dedicam-se a fazer conhecer e promover as suas actividades e serviços. Os fabricantes, enfim, contentam-se em promover os seus produtos. O PowerPoint ganhou bem a preferência de utilizadores muito variados e permite abordar todos os temas.

\section{Os tipogramas, imagens textuais}

13 Exceptuando os títulos e as legendas das ilustrações, as imagens textuais apresentam-se nos documentos sob 3 formas. O recurso a listas com marcas é massivo, $86 \%$ dos utilizadores usam-nas. Existe sem dúvida espaço para inquietação, com Tufte (2006) desta verdadeira epidemia de recurso a esta forma de esquematização verbal. Shaw et al. (1998) tinham insistido bem nos inconvenientes destas listas, sobre a imprecisão que estas geram já que não permitem mais que enumerar os pontos sem revelar as bases da sua eventual ordenação. Convém no entanto notar que a inquietação de Tufte, que via autores recorrer a uma hierarquização desenfreada das listas com marcas, deve ser moderada : a média mostra que a utilização limita-se a 2 níveis hierárquicos e apenas 5 autores usam o número máximo aqui encontrado, de 4 níveis.

14 O texto apresenta-se quase tão frequentemente sobre a segunda forma, a discursiva, em $77 \%$ dos utilizadores. Mais raros são os recursos às esquematizações textuais sobre a forma de organigramas variados. Os dados mostram bem que, a maioria do tempo, não se trata de uma alternativa na medida em que uma trintena de autores associam as duas formas mais correntes (listas e textos discursivos) e uma outra trintena as 3 formas de texto numa mesma apresentação.

15 As categorias de autores diferenciam-se pouco no que diz respeito ao recurso às diferentes formas de texto, ainda que, proporcionalmente, os fabricantes e, e termos médios, os consultores, recorram de forma mais importante que os outros aos organigramas.

16 A complementaridade das variantes textuais parece então frequentemente explorada. Mas esta aparente harmonia mascara uma certa confusão. Constatámos, com efeito, que de uma página à outra, um terço dos autores passam, no âmbito de uma mesma apresentação com marcas, de listas para textos discursivos. Ora, importa recordar que a lista com marcas remete a um comentário, habitualmente oral, devido à sua estrutura sintáctica deixar margem à interpretação, enquanto o texto discursivo é em princípio autónomo (Desnoyers, 2005b ; Doumont, 2005). As duas formas encontram na verdade a sua utilização óptima em diferentes tipos de documentos, a lista com marcas convindo mais ao oral, o texto discursivo ao impresso ou à apresentação sobre um ecrã de visualização. A coabitação das duas formas num mesmo texto traz, sem dúvida, frequentemente a confusão entre a função de diferentes escritos, confusão mantida pelo PowerPoint no que Tufte (2006) denuncia justamente sob o nome de "estilo cognitivo" do programa. 


\section{Imagens não textuais}

17 Reagrupámos neste vocábulo 3 categorias funcionais de imagens. Uma primeira reagrupa os cosmogramas, representações esquemáticas ou fotográficas de entidades materiais, o que inclui as reproduções de páginas ou de extractos de páginas encontradas nos sítios Internet mostrados em referência; tratam-se então aqui de imagens icónicas que têm claramente uma função denotativa. Uma segunda categoria reagrupa as imagens ornamentais que não têm vocação informativa específica e não têm aparentemente outra função que embelezar as apresentações; elas são frequentemente encontradas em gráficotecas e são da natureza dos "clip arts" do sistema operativo "Office". Uma terceira comporta as que apresentam os dados de estudos, sobretudo quantitativos, sobre a forma de quadros e de analogramas ; neste último tipo de imagens, encontramos essencialmente histogramas e alguns curvigramas simples.

Quadro 1: Os tipos de imagem

\begin{tabular}{|l|l|l|l|l|l|}
\hline $\begin{array}{l}\text { Tipo de } \\
\text { Imagem }\end{array}$ & $\begin{array}{l}\text { Páginas com } \\
\text { imagem } \\
\text { do total) }\end{array}$ & $\begin{array}{l}\text { Número de de } \\
\text { utilizadores }\end{array}$ & $\begin{array}{l}\text { Páginas } \\
\text { totais do } \\
\text { utilizador }\end{array}$ & $\begin{array}{l}\text { Tamanho } \\
\text { documento } \\
\text { utilizador : Média } \\
\text { (Mediana) }\end{array}$ & $\begin{array}{l}\text { Número e de } \\
\text { páginas por } \\
\text { utilizador }\end{array}$ \\
\hline Fotos & $112(4)$ & 19 & 434 & $22,8(24)$ & $5,9(26)$ \\
\hline Esquemas & $261(10)$ & 41 & 1169 & $22,3(26)$ & $6,4(22)$ \\
\hline Analogramas & $110(4)$ & 28 & 828 & $29,6(28)$ & $3,9(13)$ \\
\hline Quadros & $126(5)$ & 38 & 1170 & $30,8(28)$ & $3,3(11)$ \\
\hline Ornamentos & $270(10)$ & 46 & 1476 & $32,1(28,5)$ & $5,9(18)$ \\
\hline $\begin{array}{l}\text { Imagens } \\
\text { importadas }\end{array}$ & $882(32)$ & 85 & 2265 & $26,6(26)$ & $10,4(39)$ \\
\hline
\end{tabular}

19 A primeira coluna apresenta o número total de páginas comportando um dado tipo de imagem no conjunto das 100 apresentações estudadas; a segunda mostra o número (sobre 100) de autores que recorreram a este tipo de imagem na sua apresentação; a terceira contém o número total de páginas das apresentações comportando cada tipo de imagem; a quarta reporta a média e a mediana do tamanho dos documentos contendo cada tipo de imagem ; a última indica, por autor, o número e a percentagem de páginas com cada tipo de imagem.

O quadro 1 apresenta o conjunto dos dados. Vemos que fotos, analogramas e quadros contribuem do mesmo modo para o total de páginas que comportam os documentos, em cerca de $4 \%$. Os esquemas, as ilustrações ornamentais encontram-se em cerca de duas vezes mais páginas. Mas estas repartições globais são enganadoras já que o número de utilizadores de cada tipo de imagem é muito variável: consideraremos separadamente o caso dos 3 reagrupamentos funcionais de imagens. 
21 Vemos primeiramente neste quadro que muito poucos autores (19\%) utilizam fotos, mas que $4 \%$ das páginas totais que elas representam fazem $26 \%$ das páginas dos documentos nas quais as encontramos : existe aqui um efeito claro de concentração (de 6 vezes) na utilização deste tipo de imagem. Acontece o mesmo com os esquemas, ainda que o efeito de concentração seja menos marcado : com 2 vezes mais utilizadores (41), passamos de $10 \%$ das páginas totais a $22 \%$ das páginas dos utilizadores, uma concentração de 2 vezes.

Nestes dois casos, importa notar que estas imagens são cerca de 5 páginas nos documentos que contêm 22 páginas em média, mais pequenos que a média geral (que é de 27,4 páginas).

É interessante debruçar-se ainda sobre os usos respectivos destes dois tipos de imagem. O cruzamento dos dados da tabela com os que dizem respeito aos autores e às temáticas fazem ressaltar que $79 \%$ dos utilizados de fotos fazem-no em documentos dedicados à promoção de um bem ou de um serviço (que, misturando todos os autores, são 40 dos 100 documentos estudados); o pequeno número de documentos (7) emanando dos fabricantes de um produto é aquele em que se faz, proporcionalmente, a maior utilização de fotos e de esquemas. Os utilizadores de esquemas são também mais frequentemente os autores de documentos de cariz promocional (53 \%) que informativo (36\%). Quanto às utilizações conjuntas dos dois tipos de imagens, as combinações mostram que 50 dos autores não utilizam fotos nem esquemas, que 40 utilizam seja um, seja o outro ( 9 com fotos unicamente e 31 com esquemas unicamente), enquanto apenas 10 utilizam ambos.

24 Fotos e esquemas são, portanto, surpreendentemente, de uso pouco difundido e o seu emprego parece aqui responder a funções bem precisas.

Por outro lado, a segunda categoria, das imagens ornamentais, é a que utilizam o maior número de autores, quase a metade; os ornamentos encontram-se sobre $18 \%$ das páginas destes documentos, uma concentração de um factor de dois relativamente à média geral, e encontram-se nos documentos maiores de todos. São ainda os consultores e os fabricantes os utilizadores mais frequentes dos ornamentos. Esta categoria de autores distingue-se então pelo recurso a todo o tipo de imagens, o que faz dos seus documentos, sem dúvida, os mais variados de todos.

26 A terceira categoria funcional de imagens não-textuais assemelha-se às que apresentam os dados quantitativos. Como mostra o quadro abaixo, os analogramas e os quadros são utilizados respectivamente por $28 \%$ e $38 \%$ dos autores. Eles são 4 a $5 \%$ do total de páginas mas concentram-se em um pouco mais de $10 \%$ das páginas dos utilizadores, ou seja, 3-4 páginas nos documentos desta vez mais longos, de uma trintena de páginas, em média. E se 52 autores não utilizam analogramas nem quadros, 30 utilizam exclusivamente seja analogramas (10), seja quadros (20), ainda que 17 utilizem ambos. São ainda os documentos dos consultores e fabricantes que fazem proporcionalmente a utilização mais intensa de analogramas e de quadros, e não os professores ou investigadores, o que surpreende.

$27 \mathrm{O}$ estudo das combinações entre os recursos às representações picturais e às apresentações de dados mostra que os documentos, quer comportem ou não imagens, comportam as mesmas proporções de representações de dados e vice-versa.

28 O PowerPoint não permite fazer tudo: $85 \%$ das apresentações comporta imagens importadas. As importações relacionam-se com fotografias, gráficos, ornamentos e a 
maior parte dos esquemas, que são habitualmente impossíveis de produzir directamente no PowerPoint. Não é então surpreendente que $32 \%$ das páginas dos documentos contenham importações.

\section{Escolhas gráficas : tipografia e formatação}

As tendências muito gerais são destacam-se em matéria de concepção gráfica dos documentos. Os autores utilizam massivamente, em $79 \%$, um modelo para criar a sua apresentação. Estes modelos podem ser encontrados na impressionante panóplia que o programa apresenta e podem também ser concebidos para ou pela organização à qual pertence o autor ou criadas segundo as necessidades de uma apresentação. o PowerPoint propõe de base uma formatação minimal que separa uma zona de título de uma zona de texto. Os autores vão mais longe, optando a maior parte das vezes, pelo menos por uma demarcação física destas zonas e muitas vezes pela junção de um logótipo ou de um identificador sobre cada página. A criação ou a escolha de um modelo facilita o trabalho de concepção do documento e dá-lhe um toque distintivo.

Dois terços dos autores optam por um fundo pálido e uma apresentação positiva, o que a maioria dos autores (Desnoyers, 2005b) reconhece como assegurando uma melhor legibilidade. Resta portanto um terço de irredutíveis, pelo que um bom número opta por uma combinação de um fundo azul com caracteres brancos, esta fórmula tendo curiosamente mantido uma certa atracção após a sua aparição nos diapositivos produzidos pela película diazo, nos anos 1960 .

31 Do lado tipográfico, destaca-se uma certa conformidade às propostas do PowerPoint : Arial, fonte por defeito do programa, é a fonte principal de metade dos autores. Times, uma das fontes mais utilizadas em tratamento de texto e impressão, fica em segundo lugar. São mais de $60 \%$ os utilizadores que com Arial e fontes semelhantes, optam pelas fontes "modernas", sem base larga, mais que pelas fontes de design mais clássico. Estas escolhas estão conformes às preconizações mais frequentes dos autores de sítios dedicados à concepção de documentos Internet. Eles utilizam essencialmente as 10 fontes de base ("core fonts") da Microsoft.

Os títulos e sub-títulos são compostos de modo homogéneo: a quase totalidade dos autores utiliza apenas uma única fonte. É no corpo do texto que a variedade está presente : mais de uma quinzena de fontes diferentes e 25 autores que utilizam mais do que uma fonte. Mas a homogeneidade entre títulos e texto é a norma, apenas 11 autores mudam de fonte entre uns e outros. O recurso a um certo código tipográfico, que demarcaria os elementos dos textos pela atribuição de uma fonte particular, é então muito rara, apenas os informáticos parecem tê-lo feito, utilizando a fonte "Courier" para distinguir os elementos de programação informática.

33 A enorme variabilidade do corpo dos caracteres utilizados é impressionante. Encontramos títulos muito pequenos, em 12 pontos, e outros muito grandes com 60 pontos. A mediana é de 40 pontos, o que é considerável e sem dúvida inutilmente grande. As flutuações dos textos são ainda mais marcadas, desde caracteres microscópios com 5 pontos (utilizados sobretudo nas notas e pés de página) até a spots com 120 pontos. Aqui, as medianas correspondem melhor aos valores habitualmente recomendados, o que não mascara o facto de que uma forte proporção de autores utiliza textos muito pequenos e textos inutilmente grandes. 

que a cor esteja disponível em microinformática há decénios, mais de metade dos autores fazem os seus textos em negro, e mais de $30 \%$ em branco : sobra apenas $16 \%$ dos autores que utilizam a cor, ainda que o azul chegue aos $10 \%$. 0 domínio do preto e branco é então ainda importante, ainda que as possibilidades de utilizar a cor para personalizar os textos sejam numerosas. Este conformismo é menos marcado pelos títulos onde pouco mais de $30 \%$ dos autores se limitam ao preto; uma percentagem equivalente opta pelo branco ou o azul e $24 \%$ dos autores fazem escolhas diversas. É surpreendente constatar o aparecimento do amarelo em $17 \%$, mas esta utilização é sempre muito marcada geograficamente e sem dúvida também culturalmente, já que é essencialmente feita pelos autores dos Estados Unidos.

Constatámos enfim que, contrariamente às críticas e receios expressas por Tufte, os autores fazem uma utilização apesar de tudo moderada das técnicas de animação. A prática mais difundida consiste em fazer deslizar um novo elemento sobre uma página existente, o que é uma forma eficaz de atrair a atenção, na medida em que, evidentemente, não se abuse. 0 mesmo no que diz respeito às técnicas de transição de uma imagem à outra. A utilização feita por apenas $22 \%$ dos autores parece marcada por um cunho de nostalgia, já que a técnica preferida consiste em imitar o deslizamento das imagens que faziam os projectores de diapositivos. Acrescentemos que nenhum dos documentos estudados continha sequências vídeo, mesmo sendo tecnicamente fácil integrar estes elementos numa apresentação.

\section{Em suma}

Importa desde já recordar que a amostragem aqui estudada só pode ser representativa da população de onde foi extraída, ou seja, as apresentações PowerPoint disponíveis na Internet à data em que a recolha foi feita. Todos os professores ou todos os consultores não fazem necessariamente a escolha de colocar as suas apresentações na Internet e é difícil imaginar os critérios que levam alguns a fazê-lo e outros não ; existe então aqui um viés em favor dos que o fazem, pelo que a importância é sempre impossível de avaliar. Seria imprudente atribuir uma significação muito geral às conclusões que podemos tirar da análise desta amostra, mesmo se algumas conclusões se notem.

Este estudo quantitativo de uma pequena amostra das apresentações PowerPoint faz sobretudo ressaltar a grande variabilidade das utilizações do programa. Todos os tipos de apresentação são possíveis nos documentos PPT. O recurso aos tipogramas, as apresentações alfanuméricas, é a mais massiva, listas com marcas e textos discursivos sendo utilizados por quase todos. As imagens assim constituídas não respondem frequentemente aos critérios habituais de concepção, ou de legibilidade (Desnoyers, 2005b ; Doumont, 2005) : textos frequentemente longos, escolha de fontes muitas vezes conformista e tipografia mal controlada, monotonia cromática. $\mathrm{O}$ recurso aos quadros numerados e às representações gráficas de dados numéricos é pouco difundida; os primeiros são utilizados de modo mais difuso, os segundos parecem concentrados em tipos particulares de apresentação de carácter científico ou sobretudo técnico. Enfim, do lado dos cosmogramas, o recurso à foto é pouco difundido e concentrado em menos de $20 \%$ dos utilizadores, o que é surpreendente. As representações esquemáticas aparecem curiosamente duas vezes mais difundidas. É talvez, enfim, para compensar uma certa aridez das suas apresentações que perto de metade dos autores acrescentam

Laboreal, Volume 5 №2 | 2009 
imagens muito diversas, que trazem pouco, ou nada, ao conteúdo informativo dos documentos mas poderiam, a seus olhos, torná-los mais atractivos. Apesar disso, os autores não parecem sucumbir de modo significativo às engenhocas em matéria de animação e de transição.

Se o PowerPoint foi desenvolvido inicialmente para facilitar a concepção de imagens a projectar, constatamos que é agora frequentemente utilizado também para conceber documentos para imprimir ou para ler sobre o ecrã do computador, por exemplo num sitio Internet. Com Yates e Orlikowsky (2007), é preciso constatar que assistimos presentemente à especiação de novos géneros comunicacionais, que continuam a evoluir. Aos que propõem estes autores, importa talvez juntar dois que os nossos resultados parecem caracterizar. Por um lado o documento com intuito promocional, surgindo de todos os tipos de contexto ; parece caracterizar-se pelo recurso importante aos organigramas e esquematizações textuais, à fotografia, aos esquemas e à ornamentação. Por outro lado, o documento de ensino que, como parecem mostrar também certos resultados de Stoner (2007), é mais avaro em ilustrações, fazendo massivamente apelo à imagem textual.

Esta especiação em curso não impede que reine uma certa confusão de géneros, entre outros quando os documentos de acompanhamento de conferências ou de cursos são colocados na Internet como documentos autónomos, o que não são. $O$ recurso frequente ao PowerPoint come instrumento de redacção de relatórios ou de briefings tem sido objecto de críticas aguerridas e bem fundadas, já que o programa, no fim de tudo, não é mais que uma apresentação de ecrãs e não de tratamento de texto.

Sem necessariamente dirigir-se à questão da caracterização das imagens utilizadas, certos estudos visaram populações particulares de autores : professores (Stoner, 2007 ; Kjeldsen, 2006), meios de negócios (Yates \& Orlikowsji, 2007), serviços governamentais (Pece, 2005). Parece-nos desejável que outros estudos sectoriais sejam planeados e que a análise formal das imagens se junte às análises de conteúdo no aparelho metodológico dos autores, para melhor caracterizar os géneros em emergência.

\section{BIBLIOGRAFIA}

Desnoyers, L. (2005 a). Les images de la communication scientifique. Communication et langages, 146, 93-113.

Desnoyers, L. (2005b). La communication en congrès. Repères ergonomiques. Québec : Presses de l'Université du Québec.

Doumont, J.L. (2005). The cognitive style of PowerPoint: slides are not all evil. Technical Communication, 52, 64-70.

Kjeld sen, J.E. (2007). The rhetoric of PowerPoint. Seminar.net, Media, technology and lifelong learning $3 / 1$.

Pece, G.S. (2005). The PowerPoint society: the influence of PowerPoint in the US Government and bureaucracy. Thèse, Virginia Polytechnic Institute, Blacksburg. 
Shaw, G., Brown, R. \& Bromiley, P. (1998). Strategic stories: how 3M is rewriting business planning. Harvard Business Review Reprint 98310, Mai-Juin.

Stoner, M.R. (2007). PowerPoint in a new key. Communication Education, 56, 354-381.

Tufte, E. (2006). The cognitive style of PowerPoint: pitching out corrupts within. In Tufte, E. (ed.), Beautiful evidence. Cheschire, CN: Graphics Press LCC.

Yates, J. \& Orlikowski, W. (2007). The PowerPoint presentation and its corollaries: how genres shape communicative action in organizations. In Zachry, M. \&Thralls, C. (eds.), The cultural turn: communicative practices in workplaces and the professions. Amityville, NY : Baywood Publishing.

\section{ANEXOS}

\begin{tabular}{|l|c|c|c|}
\hline & $\begin{array}{c}\text { Média }+/ \cdot \\
\text { desvio padrão }\end{array}$ & Minimo/máximo & Mediana \\
\hline Páginas & $27,4 \pm 17,7$ & $1 / 112$ & 25 \\
\hline Megabytes & $1,45 \pm 2,07$ & $0,056 / 10,1$ & 0,65 \\
\hline \multicolumn{2}{|l}{} \\
\hline
\end{tabular}

\begin{tabular}{|c|c|c|c|c|c|}
\hline 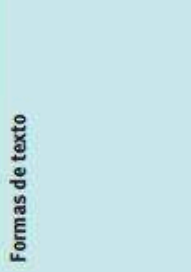 & 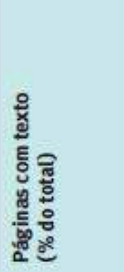 & 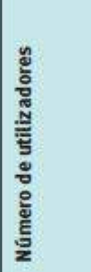 & 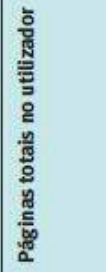 & 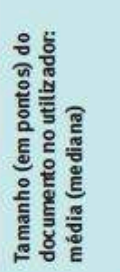 & 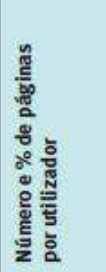 \\
\hline Listas com marcas & $1007(36,8)$ & 86 & 2512 & $29,2(26)$ & $\begin{array}{c}11,7 \\
(40,0 \%)\end{array}$ \\
\hline Texto discursivo & $925(37,8)$ & 77 & 2291 & $29,8(27)$ & $\begin{array}{c}12,0 \\
(40,4 \%)\end{array}$ \\
\hline Organigrama & $248(9,1)$ & 42 & 1467 & $34.9(29)$ & $\begin{array}{c}5.9 \\
(16,9 \%)\end{array}$ \\
\hline
\end{tabular}




\begin{tabular}{|l|c|c|c|}
\hline & Minimo & Máximo & Média (mediana) \\
\hline Títulos & 12 & 66 & $37,1(40)$ \\
\hline Sub-títulos & 12 & 60 & $31,1(30)$ \\
\hline O maior texto & 10 & 120 & $30,1(28)$ \\
\hline O texto mais pequeno & 5 & 31 & $16,5(16)$ \\
\hline Quadro III: O tamanho dos caracteres & & \\
\hline
\end{tabular}

\begin{tabular}{|l|c|c|c|c|c|}
\hline & Preto & Amarelo & Branco & Azul & Outros \\
\hline Titulos & 31 & 17 & 15 & 13 & 24 \\
\hline Texto & 53 & 0 & 31 & 10 & 6 \\
\hline
\end{tabular}

\section{RESUMOS}

Apresenta-se um estudo quantitativo dos formatos de exibição usados em apresentações PowerPoint. 0 estudo é baseado numa amostra aleatória de 100 apresentações disponíveis na Internet e considera o uso de texto, gráficos e figuras pelos autores, em relação com o conteúdo e o propósito da apresentação. Os autores utilizam massivamente o texto, quer discursivo ou, em $86 \%$ dos casos, listas com marcas. São concebidas usando sobretudo as fontes por defeito, frequentemente em tamanhos ou muito pequenos ou muito grandes e muito poucas cores. Gráficos e tabelas constituem apenas 4 a $5 \%$ do total de páginas, sobretudo em apresentações científicas ou técnicas; estas últimas são utilizadas por um maior número de autores. Reproduções fotográficas de objectos ou lugares estão surpreendentemente limitadas a menos de $20 \%$ das apresentações e $4 \%$ do número total de páginas, mas constituem $26 \%$ das páginas quando usadas, indicando assim um tipo especializado. Esquematizações são muito mais frequentes, e quase metade dos apresentadores usam elementos ornamentais tais como o Clip Art. A análise de imagens parece ser uma técnica interessante na tentativa de caracterização de tipos de apresentações.

Se presenta un estudio cuantitativo de los formatos de exhibición usados en presentaciones PowerPoint. El estudio está basado en un muestreo aleatorio de 100 presentaciones disponibles en Internet y considera el uso del texto, gráficas y figuras por los autores, en relación con el contenido y el propósito de la presentación. Los autores utilizan masivamente el texto, tanto discursivo o, en el $86 \%$ de los casos, listas con marcas. Son concebidas usando sobretodo las fuentes por defecto, frecuentemente en tamaños o muy pequeños o muy grandes y muy pocos colores. Gráficas y tablas constituyen apenas del 4 al $5 \%$ del total de páginas, sobretodo en presentaciones científicas o técnicas; estas últimas son utilizadas por un mayor número de autores. Reproducciones fotográficas de objetos o lugares están sorprendentemente limitadas a menos del $20 \%$ de las presentaciones y $4 \%$ del número total de páginas, pero constituyen el $26 \%$ 
de las páginas cuando usadas, indicando así un tipo especializado. Esquematizaciones son mucho más frecuentes, y casi la mitad de los presentadores usan elementos ornamentales tales como el Clip Art. El análisis de imágenes parece ser una técnica interesante en el intento de caracterización de tipos de presentaciones.

Il s'agit d'une étude quantitative des usages de Power-Point dans des présentations. Elle est basée sur un échantillon aléatoire de 100 présentations disponibles sur Internet et analyse l'usage de textes, de graphiques et de figures par les auteurs, en établissant des relations avec le contenu et les objectifs de la présentation. Les auteurs utilisent massivement le texte, qu'il soit discursif ou, dans $80 \%$ des cas, repris en listes à puces. Ces textes sont conçus fréquemment en recourant par défaut à leurs sources, et le plus souvent en utilisant des dimensions soit très petites soit très grandes et avec peu de couleurs. Les graphiques et tableaux constituent seulement 4 à $5 \%$ du total des pages, principalement dans les présentations scientifiques ou techniques; les derniers sont utilisés par la majorité des auteurs. Les reproductions photographiques d'objets ou de lieux sont, de façon surprenante, limitées et correspondent à moins de $20 \%$ des présentations et $4 \%$ du nombre total des pages, tout en constituant $26 \%$ des pages qui y ont recours, mettant ainsi en évidence un certain type de spécialisation. Les schémas sont beaucoup plus fréquents, et près de la moitié des présentateurs utilisent des éléments d'ornementations graphiques comme le Clip Art. L'analyse des images semble être une technique intéressante pour un essai de caractérisation d'une typologie des présentations.

A quantitative study of display formats used in PowerPoint presentations is reported. The study was based on a random sample of 100 presentations available on the net and considers the use of text, graph and pictures by the authors, in relation to content and purpose of the presentation. Authors rely massively on text, whether discursive or, in $86 \%$ of cases, bullet lists. These are designed using mostly default fonts, frequently in either too small or too large sizes and very little colour. Graphs and tables only make 4 to $5 \%$ of total pages, mostly in scientific or technical presentations; the latter are used by a larger number of authors. Photographic reproductions of objects or places are surprisingly limited to less than $20 \%$ of presentations and $4 \%$ of total pages, but constitute $26 \%$ of pages when used, thereby indicating a specializing genre. Schematizations are much more frequent, and almost half of presenters use ornamental elements such as clip art. Image analysis seems to be an interesting technique in attempts at characterizing genres of presentations.

\section{ÍNDICE}

Mots-clés: PowerPoint, images, type

Palavras-chave: PowerPoint, imagem, tipo

Keywords: PowerPoint, image, genre

Palabras claves: PowerPoint, imagen, tipo

\section{AUTORES}

\section{LUC DESNOYERS}

Université du Québec à Montréal, Montréal (Québec) H3C 3P8

desnoyers.luc@videotron.ca 